\title{
JANE AMAVA HELEN QUE NÃO SABIA BEM SE AMAVA JANE QUE \\ TAMBÉM AMAVA BLANCHE: HETEROSSEXUALIDADE \\ COMPULSÓRIA EM UMA LEITURA QUEER DE JANE EYRE DE \\ CHARLOTTE BRONTË
}

\author{
JANE LOVED HELEN WHO WAS NOT SURE IF SHE LOVED JANE WHO ALSO \\ LOVED BLANCHE: COMPULSORY HETEROSEXUALITY IN A QUEER \\ READING OF CHARLOTTE BRONTË'S JANE EYRE
}

\author{
Ruan Nunes Silva ${ }^{1}$
}

\begin{abstract}
RESUMO: Desde a sua publicação, Jane Eyre, romance de estreia de Charlotte Brontë, tem sido estudado e analisado sob várias perspectivas. Entretanto, considerando que poucos trabalhos no Brasil têm abordado a obra sob um viés Queer, proponho ler duas famosas cenas do romance para ilustrar a discussão de como a heterossexualidade compulsória, conforme discutido por Adrienne Rich (2003), se tornou um mecanismo de apagamento da atração e do desejo que Jane sente por Helen Burns e Blanche Ingram, duas outras personagens do romance. Enriquecendo a discussão, utilizo ainda dois ensaios de Sigmund Freud $(1996,2007)$ para ressaltar como se dá a construção do desejo de Jane pelas duas supracitadas personagens.
\end{abstract}

PALAVRAS-CHAVE: Jane Eyre; Queer; Heterossexualidade compulsória.

ABSTRACT: Since its publication, Jane Eyre, Charlotte Brontë's debut novel, has been studied and analysed from a myriad of perspectives. However, considering that few essays in Brazil approach the novel from a Queer standpoint, I propose to investigate and analyse two well known scenes from Jane Eyre to illustrate the discussion of how compulsory heterosexuality, as discussed by Adrienne Rich (2003), has become a means to erase both the attraction and desire which Jane feels towards Helen Burns and Blanche Ingram, two other female characters in Brontë's novel. So as to enrich the discussion, I also tackle two essays written by Sigmund Freud (1996, 2007) to highlight how Jane's desire towards the aforementioned characters is constructed.

KEYWORDS: Jane Eyre; Queer; Compulsory heterosexuality.

Publicado em 1847, Jane Eyre se tornou um dos romances vitorianos mais lidos e estudados ao redor do mundo. Escolhido como parte das leituras obrigatórias em escolas e universidades, Jane Eyre também alcança diversos leitores através de clubes de leitura que buscam oferecer uma visão do período vitoriano. Entretanto, a visão do romance de estreia de

\footnotetext{
${ }^{1}$ Doutorando em Estudos de Literatura pela Universidade Federal Fluminense e Professor Assistente de Língua Inglesa e Literaturas de Língua Inglesa da Universidade Estadual do Piauí.
} 
Charlotte Brontë como fundamentalmente coerente com os valores vitorianos tem sido pouco a pouco desconstruída e colocada em xeque.

Segundo o professor da UFG Alexander Meireles da Silva, o período vitoriano se traduziu em um "rígido código de conduta social" (2006, p. 225): jogos e bebidas se tornaram práticas indecentes para cavalheiros e criou-se a expectativa de que as mulheres emulassem o Anjo da Casa, ou seja, elas deveriam se ater ao modelo de fragilidade e prudência estabelecido. (SILVA, 2006, p. 225) Entretanto, não é necessário ressaltar a hipocrisia que reinava por baixo dessas rígidas regras sociais, bastando apenas ler as peças de Oscar Wilde que representam finamente a decadência do período vitoriano sem perder a atenção ao estético da época.

Pensar o romance Jane Eyre como uma visão do mundo vitoriano não se sustenta mais no século XXI. Existem, sim, questões não apenas estéticas, porém temáticas, que tornam o romance um livro de sua época, mas se faz vital oferecer novas interpretações deste que se tornou um ícone de leitores que o chamam de um romance protofeminista.

Uma leitura que destoa dos valores associados ao período vitoriano é a que se refere à repressão sexual. Conforme apontado pela crítica Elaine Showalter (2012), os críticos de Jane Eyre à época da publicação estavam obcecados em descobrir o sexo biológico de Currer Bell, o pseudônimo usado por Brontë ao publicar o romance, o que nos leva a pensar sobre quão (não) preocupados em ler alguns subtextos da obra eles realmente estavam. Showalter cita como descrições de roupas, detalhes domésticos e conversas levaram os críticos a designar que o romance teria sido escrito por um homem ou uma mulher, pois apenas uma pessoa de determinado sexo biológico poderia saber tanto sobre estofamento, por exemplo. É curioso, no entanto, ler como autores da época buscaram categorizar Jane Eyre como a coisa menos feminina já lida ou mesmo o livro masculino com mais vigor que já fora escrito. (SHOWALTER, 2012, p. 76)

É perceptível nos escritos de Showalter que as críticas sobre Jane Eyre se preocupavam em analisar quão masculina ou feminina seria a escrita, pois assim poderiam saber se o romance fora de fato escrito por um homem ou uma mulher. Essa preocupação sexista acabou apagando o subtexto erótico homoafetivo presente no romance. Uma razão possível e crível é a própria construção da identidade feminina como fixa e estável: se uma mulher não poderia nem mesmo escrever um romance tão intenso quanto Jane Eyre, por que algum crítico se preocuparia em desenvolver uma leitura privilegiando o despertar sexual de uma protagonista que, não apenas em teoria, quebra e mantém no lugar as estruturas e expectativas vitorianas? 
Além disso, cabe aqui uma reflexão teórica que coaduna não só com o questionamento anterior, mas também com as leituras propostas aqui de Jane Eyre: repensar a literatura como lócus de perpetuação da heterossexualidade compulsória. Em outras palavras, proponho dialogar com uma perspectiva teórica queer que questiona a heteronormatividade como o padrão imposto.

Traduzido como estranho, raro ou excêntrico, o termo queer tem sido utilizado constantemente em leituras contemporâneas com o objetivo de realçar a noção da tecnologia da normalização. Em outras palavras, queer significa "colocar-se contra a normalização" (LOURO, 2016, p. 39), evidenciando a construção de binarismos para representar "a diferença que não quer ser assimilada ou tolerada." (idem) O que originalmente era um termo pejorativo assumiu uma perspectiva transgressora ao demonstrar como existe uma lógica embrenhada nas relações de poder para manter estáveis estruturas como gênero e sexualidade. Ainda de acordo com Guacira Lopes Louro, queer "é estranho, raro, esquisito (...) é também o sujeito da sexualidade desviante - homossexuais, bissexuais, transexuais, travestis, drags." (LOURO, 2016, p. 7) Isto significa que uma leitura queer busca desconstruir a própria compreensão de um sujeito como heterossexual em sociedade, pois quem perturba a norma heterossexual é a presença de homossexuais e bissexuais.

Ao resistir ao modelo de estabilidade heteronormativa, o queer "dramatiza as incoerências nas supostamente estáveis relações entre sexo cromossômico, gênero e desejo sexual" (JAGOSE, 1996, p. 3) Dessa forma, o queer demonstra a impossibilidade de uma sexualidade natural e dada ao colocar em discussão termos que são aparentemente inocentes como homem, mulher e heterossexual. Será a partir desta perspectiva que o queer servirá como instrumento político de crítica cultural e social, apontando as incoerências nos discursos que buscam homogeneizar indivíduos e apagar aqueles que destoam da norma. Um desses discursos é a compreensão da heterossexualidade como inata e natural.

De maneira breve, heterossexualidade compulsória, nas palavras da escritora e teórica Adrienne Rich, se refere aos meios como a heterossexualidade se estrutura como uma instituição e é "imposta, controlada, organizada, propagandeada e mantida à força" (RICH, 2003, p. 27) Isto significa enxergar como a maternidade, a exploração econômica, a família nuclear entre outras (ainda) são meios de controlar as mulheres e moldá-las a partir dos preceitos de uma sociedade que se diz liberal e progressista.

Segundo Rich, pensar a heterossexualidade como a inclinação natural, emocional e sensual para mulheres, as vidas que não se encaixam nesse continuum são vistas como desviadas e, se não silenciadas ou apagadas, são patologizadas. (RICH, 2003, p. 30) Enxergar 
que a heterossexualidade foi imposta de maneira forçada e subliminar também significa enxergar de que maneiras essa opressão se concretizou e tomou forma. Dessa maneira, proponho ler Jane Eyre colocando em discussão como a heterossexualidade compulsória se tornou parte das críticas e leituras do romance, privilegiando dois momentos que considero fundamentais para entender a sexualidade da protagonista Jane.

Duas cenas serão relevantes para a minha discussão de como Jane Eyre já trazia em seu cerne a discussão da sexualidade feminina como elemento da heterossexualidade compulsória. A primeira é o momento em que Helen Burns, amiga de Jane, falece em Lowood e a segunda é a criação artística de Jane, já mais velha, após ouvir a descrição de Blanche Ingram. Ao reler esses dois breves trechos, indago como, atendendo aos padrões vigentes não apenas à época, pois a heterossexualidade compulsória se constitui ainda como instituição, o romance minimiza uma existência lésbica, apagando-a de possíveis discussões.

Se mesmo sem nomear como homossexualidade, gays e lésbicas já eram considerados abjetos por perturbarem a ordem e o sistema, não é, pois, uma surpresa que aproximar Jane Eyre e uma leitura queer constitua uma fonte epistemológica desconfortável para certos leitores. Vale lembrar que falar de queer não significa "uma defesa da homossexualidade" conforme apontado pelo sociólogo Richard Miskolci, mas sim uma "recusa dos valores violentos que instituem e fazem valer a linha da abjeção [no sentido kristeviano].” (MISKOLCI, 2016, p. 24)

\section{Cena um: objeto e alvo sexuais}

A primeira cena se passa no capítulo IX quando Jane, então uma jovem menina, entra no quarto onde Helen está acamada. A cena se passa em Lowood, a instituição de caridade para a qual Jane é enviada por sua tia e onde ela recebe uma rígida educação na qual as alunas precisam aprender a ser pacientes e altruístas sob medidas que beiravam a tortura. Em um ambiente tão hostil, a pessoa com quem Jane parece estabelecer uma conexão mais próxima é Helen Burns. Será essa conexão que, até então tem sido interpretada como uma amizade inocente entre duas meninas, se tornará central para a segunda cena que utilizarei adiante.

Ao entrar no ambiente onde Helen se encontrava, Jane inicia uma conversa que se centra em uma discussão filosófica acerca da dualidade entre vida e morte que culmina com Helen convidando Jane para deitar ao seu lado na cama: “Jane, your little feet are bare; lie 
down and cover yourself with my quilt.' I did so: she put her arm over me, and I nestled close to her."2 (BRONTË, 2012, p. 76)

A escolha lexical é extremamente simbólica para expressar quão próximas elas estão, já que o uso do verbo "nestle" significa "aninhar-se", ou seja, estar muito próximo de alguém fisicamente, como se buscasse um ninho. Esse lugar de conforto entre as duas é criado para firmar a ligação que se pretendia ser amistosa apenas, porém a tensão permanece no ar após o fim da conversa de Jane e Helen: “my face against Helen Burns' shoulder, my arms around her neck. I was asleep, and Helen was - dead."33 (BRONTË, 2012, p. 77)

A morte da Helen serve como uma forma de minimizar a tensão sexual que existe entre as duas meninas, afinal, quem poderia pensar em uma relação entre duas mulheres? Tal comentário remete ao próprio mito de que a Rainha Vitória teria dito que não era necessário proibir as relações entre mulheres, uma vez que elas jamais se envolviam da mesma maneira que os homens gays. A morte de Helen pode ser interpretada de maneiras diversas, porém a leio aqui como um trauma que dará espaço para o trabalho de luto que Jane viverá mais tarde no romance.

Previamente, Helen representara a salvação ao "resgatar" Jane de seu castigo durante uma aula. Isso apenas fortifica a admiração que uma tem pela outra e ilustra a própria reflexão de Freud acerca da atração/desejo em "Drei Abhandlungen zur Sexualtheorie" que viria a ser traduzido para o português como "Três Ensaios sobre a Teoria da Sexualidade", trabalho relevante para compreender melhor como a pulsão sexual está presente na infância.

No referido trabalho, Freud diferencia objeto sexual e alvo sexual: o primeiro seria aquele de quem emana a atração sexual e o segundo seria aquele para quem a atração se direciona. Tal diferenciação estaria completa caso o mundo de fato se dividisse em uma maneira simples e direta, como se a pulsão sexual fosse expressa na poética fábula da divisão do ser humano entre duas metades, homem e mulher. (FREUD, 2007, p. 15) Isso significa que Freud já alertava sobre a impossibilidade de dividir o mundo em uma visão binária, por mais que seus trabalhos não tenham oferecido uma perspectiva profunda de tal. Já no início do ensaio, Freud chama atenção para a "surpresa" de que o período da infância fosse destituído de qualquer pulsão sexual - tal qual a sociedade vitoriana acreditava - e que homens poderiam ter homens como seu alvo assim como mulheres poderiam ter outras mulheres como o seu.

\footnotetext{
2 “'Jane, seus pezinhos estão descalços; deite-se e cubra-se com minha colcha' Assim fiz: então ela colocou seu braço sobre mim e eu me aninhei próximo a ela.” (BRONTË, 2012, p. 76, minha tradução)

3 "meu rosto pressionando o ombro de Helen Burns, meus braços ao redor do pescoço dela. Eu estava dormindo, e Helen estava - morta." (BRONTË, 2012, p. 77, minha tradução)
} 
Acreditando que a relação entre Jane e Helen pode ser lida a partir da ótica freudiana supracitada, considero importante traçar um paralelo com os atos de olhar e tocar, atos estes que se desenvolvem já no início do romance.

Jane já havia encontrado Helen no início do capítulo $\mathrm{V}$, porém é próximo ao final deste que ela admira a "amiga" por sua postura ao aceitar a punição de Miss Scatcherd, uma das professoras em Lowood. Jane nota como Helen não se abate pela punição, mantendo-se ereta como se pensasse em outra coisa além:

How can she bear it so quietly-so firmly?' I asked of myself. 'Were I in her place, it seems to me I should wish the earth to open and swallow me up. She looks as if she were thinking of something beyond her punishment-beyond her situation: of something not round her nor before her." (BRONTË, 2012, p. 46) ${ }^{4}$

Ao final do capítulo $\mathrm{V}$ é perceptível uma admiração por parte de Jane que olha e contempla Helen. Inicialmente, essa admiração seria elemento que alimentaria a amizade de ambas, porém, longe de discordar com tal ideia, trago para a mesa outra leitura: o olhar de Jane já denotava um elemento queer nessa relação. Conforme Freud afirma em "Três Ensaios sobre a Teoria da Sexualidade", olhar e tocar são indispensáveis para atingir o alvo sexual. (FREUD, 2007, p. 36)

Se no capítulo V Jane olha para Helen, é no capítulo VII que Jane e Helen se tocam pela primeira vez, logo após Jane sofrer um castigo na escola. Helen acalma Jane e as duas se aproximam fisicamente: Jane com a cabeça no ombro e com os braços ao redor de Helen:

Resting my head on Helen's shoulder, I put my arms round her waist; she drew me to her, and we reposed in silence. We had not sat long thus, when another person came in. Some heavy clouds, swept from the sky by a rising wind, had left the moon bare; and her light, streaming in through a window near, shone full both on us and on the approaching figure, which we at once recognised as Miss Temple. (BRONTË, 2012, p. 65)

Há algo curioso na própria construção textual: enquanto as meninas estão finalmente fisicamente próximas, elas permanecem em silêncio até o momento em que alguém entra no

\footnotetext{
4 'Como ela consegue aguentar tão quieta - tão firme?'Eu me perguntei. 'Estivesse eu no lugar dela, acredito que eu desejaria que a terra se abrisse para me engolir. Ela aprece como se estivesse pensando em algo além de sua punição - além de sua situação: em algo que não está nem ao redor nem diante dela.' (BRONTËं, 2012, p. 46, minha tradução)

${ }^{5}$ Com a cabeça no ombro de Helen, coloquei meus braços ao redor da cintura dela; ela me puxou para perto e repousamos em silêncio. Mal havíamos sentado quando outra pessoa entrou. Algumas nuvens pesadas, varridas do céu por um vento cortante, tinham deixado a lua descoberta; e sua luz, entrando por uma janela próxima, brilhava em cima de nós duas e também na figura que se aproximava, que nós imediatamente reconhecemos como Miss Temple. (BRONTË, 2012, p. 65, minha tradução)
} 
mesmo ambiente e é delatado pela lua. Simbolicamente, a noite é o período onde, por estar reinando a escuridão, nada esteja tão claro quanto durante o dia. Permitir-se-ia assim que a relação entre Jane e Helen ficasse longe dos olhos do público, porém a própria lua delata as meninas, revelando-as. A vingança do símbolo-mor da feminilidade.

O que o trecho de Jane Eyre citado acima demonstra é a indispensabilidade do olhar e do toque para alcançar seu alvo sexual. Jane não hesita em estar fisicamente perto de Helen, assim como revela o trecho supracitado do capítulo IX, quando Helen falece. Inicialmente o olhar e, mais tarde, o tocar - exatamente conforme a interpretação freudiana explicita. $\mathrm{O}$ fundador da psicanálise diz que uma dose de toque/tocar é indispensável para alcançar o alvo sexual e que a impressão visual é um caminho pelo qual a excitação da libido geralmente é acordada. (FREUD, 2007, p. 36) Portanto, ler essas cenas no início de Jane Eyre colocando em evidência o apagamento da ligação (bonding) entre essas duas meninas é uma forma de demonstrar a construção da heterossexualidade compulsória, conforme afirmado por Adrienne Rich.

Ao construir a ligação entre Helen e Jane como uma amizade jovial, as leituras do romance evidenciaram o papel de Helen até mesmo como uma mãe para a órfã Jane. Entretanto, por muitos anos, preferiu-se investigar a ligação como uma amizade e não como uma relação entre objeto e alvo sexuais. Privilegiou-se até mesmo, por exemplo, ler a referida ligação como uma sintomática forma da visão vitoriana sobre as doenças da época.

Em Somatic Fictions, Athena Vrettos investiga as doenças, especialmente aquelas psicossomáticas, como construções imaginativas no período vitoriano. Em sua análise, Vrettos utiliza autores como Elizabeth Gaskell, Henry James, George Eliot, Bram Stoker entre outros, demonstrando uma longa e consistente pesquisa que aponta a interpretação de certas doenças e condições físicas como obstáculos para que as mulheres alcançassem certas posições sociais. O que me interessa no estudo de Vrettos é a maneira utilizada pela teórica para analisar como a posição da função das enfermeiras foi apropriada com fins segregatórios em certos romances.

Vrettos afirma que o conflito entre a construção médica da susceptibilidade emocional feminina e a patologização do excesso emocional feminino é claramente expressa nas ficções vitorianas que destacam as habilidades interpretativas das enfermeiras. (VRETTOS, 1995, p. 29) Como exemplo, a autora utiliza a obra Hospital Sketches de Louisa May Alcott, famosa por Little Women, para demonstrar em comparação com outros romances a forma como a função da enfermeira serviu para perpetuar um estereótipo do feminino no lidar com doenças. 
A enfermeira assume um papel fundamental na reconstrução da identidade fragmentada do paciente ao ler sua alma através de seu corpo (VRETTOS, 1995, p. 31), enfatizando o traço associado ao feminino já no período vitoriano. Se o feminino era relacionado à susceptibilidade emocional e aos excessos, a enfermeira é a ligação entre o comunicável e o incomunicável, entre o que se pretende falar e aquilo que não se permite falar. Segundo a própria Alcott, no caso de alguns pacientes, a mente sofreu mais que o corpo, requisitando as habilidades interpretativas de uma enfermeira. (ALCOTT apud VRETTOS, 1995, p. 31)

Se a enfermeira enquanto função social representava o feminino que consegue equilibrar dois mundos, o masculino como comunicável e o feminino como incomunicável, esta profissão representa a divisão entre gênero e emoção, perpetuando o estigma vitoriano de que as mulheres são mais propensas aos percalços emocionais. Logo, faz-se vital que a enfermeira esteja perto para cuidar não apenas da doença em questão, mas também para deixar certos elementos em seus "devidos lugares".

Essa reflexão promovida por Vrettos suscita outra questão: Teria Jane exercido a função de enfermeira enquanto Helen estava doente? Lendo novamente o trecho que culmina na morte de Helen, o diálogo assume tons metafísicos ao refletir sobre o que aconteceria após a morte terrena: segundo Helen, ela iria para uma "região de felicidade". (BRONTË, 2012, p. 76) O diálogo é lido como uma conversa pueril e jovem justamente pela compreensão de que Jane estaria cuidando de Helen em seu leito de morte, mesmo após Jane ter expressado previamente que precisava ver Helen e dar-lhe um último beijo: "for I must see Helen - I must embrace her before she died - I must give her one last kiss, exchange with her one last word." (BRONTË, 2012, p. 75, ênfase no original) ${ }^{6} \mathrm{O}$ uso do modal "must", que tem sentido de obrigação, revela o desespero de Jane ao pensar sobre a morte de Helen e é justamente a interpretação de Jane como enfermeira que mascara a leitura de seu desejo pela moribunda.

Ao ler Jane como exercendo a função de enfermeira, apagam-se as marcas do desejo e oferece-se, consequentemente, uma cena que enfatiza o laço de amizade e não a tensão sexual entre as duas. Cuidar daquela que agoniza desloca a relação de objeto e alvo sexuais para alimentar a hermenêutica da naturalização do afeto como aspecto essencialmente feminino propagada por médicos no período vitoriano. (VRETTOS, 1995, p. 24)

Brevemente, partindo da compreensão do olhar e tocar de Freud e me apropriando da descrição da função das enfermeiras na literatura vitoriana de Vrettos, aponto que existe algo

\footnotetext{
6 "Eu preciso ver Helen - Eu tenho que abraçá-la antes que ela morra - Eu preciso dar um último beijo, trocar com ela uma última palavra." (BRONTË, 2012, p. 75, minha tradução)
} 
queer na relação entre Jane e Helen, especialmente quando se considera que a relação destas tem sido lida como juvenil e pueril. Ao compreender a posição de Jane como enfermeira, aquela que cuida do incomunicável feminino, aquela que olhou e tocou Helen, é possível notar que leitores de Jane Eyre ainda interpretam o romance a partir da construção da heterossexualidade compulsória: são apenas amigas e nada mais. Entretanto, há algo presente nessa caixa de pandora que não foi questionado ainda.

\section{Cena dois: arte e ciúmes?}

É de meu interesse apontar outra cena que flerta diretamente com uma perspectiva queer: a pintura feita por Jane de como Blanche Ingram seria fisicamente. A cena é inicialmente interpretada como uma cena de ciúmes, pois Jane não conseguia compreender como Mr. Rochester poderia se apaixonar por ela, uma vez que ela era apenas mais uma criada enquanto Blanche seria uma mulher mais adequada devido ao seu background. Entretanto, proponho investigar como essa mesma cena pode ser lida de maneira semelhante aos trechos anteriores.

Algum tempo após deixar Lowood para se tornar uma preceptora em Thornfield Hall, Jane se descreve como apaixonada por Mr. Rochester, seu patrão na nova residência. Assim como outros romances da época, será essa ligação amorosa que será explorada pela obra. No entanto, ao se comparar com Blanche, de quem ouvira falar, Jane se enxerga como menos capaz de encantar Rochester, afinal, ela era apenas uma empregada sem um passado de valor: “'YOU,' I said, 'a favourite with Mr. Rochester? YOU gifted with the power of pleasing him? YOU of importance to him in any way? Go! your folly sickens me." (BRONTË, 2012, p. $154)^{7}$

O que surpreende vem após Jane repetir para si mesma que confundira expressões de apreciação de Rochester com sinais de que ele estaria apaixonado por ela. Jane se compromete a realizar um desenho de si e depois um de Blanche Ingram seguindo a descrição dada por Mrs. Fairfax, a governanta de Thornfield Hall.

'Listen, then, Jane Eyre, to your sentence: tomorrow, place the glass before you, and draw in chalk your own picture, faithfully, without softening one defect; omit no harsh line, smooth away no displeasing irregularity; write under it, 'Portrait of a Governess, disconnected, poor, and plain.'

\footnotetext{
7 'VOCÉ', eu disse, 'uma favorita para Mr. Rochester? VOCÊ dotada com o poder de agradá-lo? VOCÊ com alguma importância para ele? Ah, vá! Sua estupidez me adoece.' (BRONTË, 2012, p. 154, minha tradução)
} 
'Afterwards, take a piece of smooth ivory-you have one prepared in your drawing-box: take your palette, mix your freshest, finest, clearest tints; choose your most delicate camel-hair pencils; delineate carefully the loveliest face you can imagine; paint it in your softest shades and sweetest lines, according to the description given by Mrs. Fairfax of Blanche Ingram; remember the raven ringlets, the oriental eye;-What! you revert to Mr. Rochester as a model! Order! No snivel! - no sentiment! - no regret! I will endure only sense and resolution. Recall the august yet harmonious lineaments, the Grecian neck and bust; let the round and dazzling arm be visible, and the delicate hand; omit neither diamond ring nor gold bracelet; portray faithfully the attire, aerial lace and glistening satin, graceful scarf and golden rose; call it 'Blanche, an accomplished lady of rank.' (BRONTË, 2012, p. $154-155)^{8}$

Apesar de longo, o trecho acima demonstra a preocupação técnica de Jane em fazer um retrato seu de maneira simples e sem detalhes para justificar quão menos importante que Blanche ela seria. Apesar disso, os detalhes que alimentam a imaginação de Jane demonstram a preocupação em não deixar nenhuma particularidade escapar. Inicialmente, essa descrição suscita a noção de que Jane não conseguia controlar seus ciúmes e precisava extravasar de alguma maneira, já que palavras não eram suficientes. Ela, então, utiliza a arte para comunicar aquilo que passa em seu interior. Não é possível discordar de que a arte se torna a linguagem pela qual Jane comunica seus sentimentos, porém o que está em jogo é que as interpretações sempre alimentam os ciúmes como elemento fundamental para definir a relação entre Jane e Blanche, especialmente ecoando a constante afirmação de médicos vitorianos de que as mulheres são mais propensas aos excessos emocionais. (VRETTO, 1995) Posso ir mais além e apontar que os ciúmes que são associados a esta cena em particular derivam da leitura de uma Weltanschauung construída a partir da heterossexualidade compulsória.

A primeira questão que parece estranha é o ato de Jane fazer um retrato de uma mulher a quem jamais conhecera e cuja descrição ouvira apenas uma vez. Os detalhes que ela procura expressar em sua arte - o busto grego, o braço deslumbrante, a mão delicada, o anel de diamante, a pulseira de ouro, os traços harmoniosos - estão de fato fixados em sua memória, deixando clara a sua obsessão por Blanche, antes mesmo de conhecê-la. Questiono então a

\footnotetext{
8 'Escute a sua sentença, Jane Eyre: amanhã, coloque um espelho à sua frente e desenhe em giz sua própria imagem, fielmente, sem amaciar qualquer defeito; não omita nenhuma linha, não suavize nenhuma irregularidade insatisfatória; escreva embaixo da imagem, "Retrato de uma Preceptora, desconectada, pobre e simples'

'Depois, pegue um pedaço de marfim - você tem um preparado na sua caixa de materiais: pegue sua paleta, misture as tonalidades mais frescas, mais finas e mais claras; escolha seus pincéis mais delicados; delineie cuidadosamente a mais amável face que você puder imaginar; pinte-a nos tonas mais suaves e nas linhas mais doces, de acordo com a descrição de Blanche Ingram dada por Mrs. Fairfax; lembre-se dos cachos, do olho oriental; - O que! Você voltou para Mr. Rochester como modelo! Ordem! Sem choramingar! Sem sentimento! Sem arrependimento! Eu aguentarei apenas razão e resolução. Lembre-se dos solenes, porém majestosos traços, do pescoço e busto gregos; deixe o pomposo e deslumbrante braço visível e a delicada mão; não omita nem o anel de diamante, nem a pulseira de ouro; retrate fielmente a vestimenta, a renda trabalhada e o brilhante cetim, gracioso cachecol e dourada rosa; chame a pintura de 'Blanche, uma respeitável dama." (BRONTË, 2012, p. 154-155, minha tradução)
} 
razão de gravar e apreciar tal reminiscência com um prazer que poderia ser descrito como sádico, afinal, desenhar a mulher que compete pela atenção daquele homem que parecia desejá-la se torna um método para veicular seus ciúmes - ou não?

A última frase do parágrafo anterior expressa bem a armadilha da heterossexualidade compulsória e cabe aqui utilizar outra reflexão de Freud para ilustrar teoricamente a tensão sexual entre Jane e Blanche. Em ensaio intitulado "Bruchstück einer Hysterie-Analyse", traduzido como "Fragmentos da Análise de um Caso de Histeria", Sigmund Freud relata o caso da paciente ficcionalmente chamada Dora. Então com 18 anos, Dora vinha de uma família composta dela mesma, seus pais e um irmão. O relato descreve o que inicialmente parecia uma família tranquila, porém o caso se revela intenso conforme o tratamento de Dora segue.

Inicialmente Dora estava acometida por sintomas somáticos e psíquicos como dispneia, tosse, afonia e enxaquecas. Do alto de sua expertise, Freud descreve como uma neurose não tão chamativa e que outros casos mais interessantes já devem ter sido publicados. (FREUD, 1996, p. 33) O caso se torna instigante quando se revela que o pai de Dora sempre fora dominador e que sua mãe jamais se posicionou frente a tal, o que alimentou a paciente a se tornar uma mulher de inteligência precoce. Quando o pai adoece e a família se muda, serão os vizinhos Sr. e Sra. K. que tornarão o caso ainda mais complexo.

O casamento dos pais de Dora era infeliz assim como o do Sr. e da Sra. K., o que acabou por distanciar os casais e aproximar outros pares: Dora começa a passar mais tempo com o Sr. K. enquanto a Sra. K. cuida de seu pai. Buscando resumir a complexidade do caso, após expressar que o Sr. K. fizera-lhe uma proposta inadequada, Dora revela o problema esperando que seu pai tivesse alguma atitude - o que não acontece. Freud aponta ainda que Dora apresentava questões após ter se sentido "traída" pela Sra. K. com quem trocara confidências íntimas e que a segunda revelara para manter o caso com o pai de Dora. Freud conclui, portanto, que a paciente se sente inevitavelmente atraída pelo pai.

O paralelo que traço aqui aponta que, assim como Dora, Jane foi interpretada unilateralmente. Freud acaba por reduzir a complexidade ao fato de que Dora estaria apaixonada por seu pai, assim como Jane tem sido interpretada como uma mulher com ciúmes de outra. Entretanto, a leitura de Lacan sobre o caso - as inversões dialéticas - serve para sustentar a hipótese de que Jane não estaria com ciúmes de Rochester, mas sim de Blanche Ingram. Cabe aqui, portanto, colocar em discussão as inversões dialéticas lacanianas que o psicanalista argentino Ricardo Horacio Etchegoyen aborda em relação ao caso Dora para contrastar com a situação de Jane. 
Partindo da discussão de Lacan sobre o caso Dora, Etchegoyen aponta que existem algumas teses e inversões dialéticas que precisam ser colocadas em destaque. A primeira tese se trata de Dora evidenciando como a relação extraconjugal de seu pai com a Sra. K. a incomodava. Em contrapartida, a primeira inversão dialética é que Dora precisaria encarar que não era apenas um "joguete das circunstâncias”, mas que tinha um papel e não era tão passiva como acreditava. (ETCHEGOYEN, 2004, p. 79) Isto significaria que Dora estaria consciente de ser cúmplice do caso extraconjugal do pai ao optar por não fazer nada.

Fazer Dora reconhecer que ela tinha benefícios com os presentes do Sr. K. e com a situação de seu pai a levam a se colocar "como autora e não mais vítima" (ETCHEGOYEN, 2004, p. 79) Tal compreensão nos leva à segunda tese que argumenta sobre como Dora não sentiria ciúmes de tal relação entre a Sra. K. e seu pai, afinal, Dora tinha uma mãe e o pai dela uma esposa. Além disso, o questionamento crescia: qual filha não teria ciúmes dessa relação extraconjugal?! Entretanto, a segunda inversão coloca em xeque essa percepção: as razões para tal ciúme não são suficientes, acredita Freud, pois a situação já era do conhecimento de Dora. Segundo a interpretação de Freud, os ciúmes que Dora sentira não eram do "conflito de rivalidade com a Sra. K., não tanto quanto amante do pai, mas como mulher do Sr. K, que é quem lhe interessa.” (ETCHEGOYEN, 2004, p. 79) Seria então o Sr. K, na leitura freudiana, o objeto de ciúmes que é mascarado pela relação entre Dora e seu pai.

Até então, as duas teses e inversões dialéticas pressupõem uma leitura do mundo a partir de uma ótica heterossexual, perspectiva esta que é deslocada quando Lacan relê o caso, conforme Etchegoyen expõe. Faltara a Freud a terceira inversão dialética que lê o vínculo homoafetivo entre Dora e a Sra. K.. Etchegoyen faz uso dos conceitos de transferência e contratransferência para centralizar que Freud, tão cego pela sua contratransferência, não operou a terceira inversão pela qual teria dito "a Dora que, por trás de seus ciúmes pelo Sr. K., estava o amor pela mulher" (ETCHEGOYEN, 2004, p. 80). Ao contrário, Freud "procura tornar Dora consciente de seu amor por K. e por outro lado, também insiste em que o Sr. K. estaria enamorado por ela. Aí Freud engancha-se na transferência e não faz a reversão do processo." (ETCHEGOYEN, 2004, p. 80)

De maneira breve, o caso de Dora, que estava ligada afetivamente a Sra. K., pode ser usado como um paralelo para a minha leitura de Jane Eyre. Assim como as teses assinaladas acima, interpreto ainda que Jane estaria em uma crise de ciúmes vinculada a Rochester, porém as inversões dialéticas aqui também funcionam. A primeira se refere ao fato de ser também conveniente para Jane representar que era uma vítima das circunstâncias, mesmo ela já tendo assumido posturas desafiadoras em diversos momentos anteriores no romance. 
Uma segunda inversão se dá ao confrontar as razões insuficientes para justificar os ciúmes de Jane. Antes de iniciar a produção artística baseada na descrição de Blanche Ingram, Jane expressa grande interesse em saber mais sobre a segunda: como ela era? Como era a sua voz? Se ela era casada? Se Rochester não tinha algum interesse nela? O interessante é notar que mesmo com a negação do interesse de Rochester nas palavras de Mrs. Fairfax, Jane insiste em se construir como aquela que está fora da relação (inexistente) entre Rochester e Blanche. É possível então apontar que os ciúmes advêm de outra causa: Jane, na realidade, está ligada afetivamente à Blanche.

Opera-se, portanto, uma inversão dialética do desejo reprimido de Jane, aquele que fora domesticado previamente através de sua representação como enfermeira no leito de Helen. O que se interpreta como ciúmes ou até mesmo inveja é, na realidade, o desejo de ter Blanche para si. Vale notar que, por não conhecer Blanche e optar por ilustrá-la, Jane expressa que o seu desejo por alguém como Blanche precisa se fazer concreto, tão concreto que precisa estar próximo de um desenho seu também, lado a lado, não como se competissem, mas como se estivessem se complementando.

Se queer subverte e desafia certas fronteiras através de exageros (LOURO, 2016), acredito que o "surto artístico" de Jane não seja apenas um momento de ciúmes, mas sim uma expressão de uma sexualidade interrompida. Incapaz de lidar com o próprio desejo, Jane precisa encontrar maneiras de se expressar e, através da imagem de Blanche, constrói uma leitura de si mesma como sujeito que, paradoxalmente, sustenta e quebra a noção de uma sexualidade coerente e inata. Sustenta por permitir que essa cena seja lida como uma expressão de ciúmes ou inveja, porém quebra ao possibilitar que se repense a cena como questionamento de si enquanto mulher heterossexual.

\section{Conclusão}

Mesclando as reflexões de Freud, Rich, Vrettos e Ethegoyen, procurei apontar como a protagonista Jane tem sido constantemente lida através de uma ótica que privilegia a sua sexualidade como uma identidade heterossexual fixa e inquestionável. Quebrando com certas restrições gendradas da época, Jane Eyre se tornou um romance constantemente associado ao feminismo pelas posições assumidas por Jane, mesmo em uma época na qual o movimento feminista não existia como tal. O perigo, entretanto, está em interpretar o romance a partir de uma visão única que apenas enxerga os movimentos individuais de Jane como elementos fundamentais de sua personalidade, ignorando assim as nuances de sua sexualidade. 
Tendo sido lida como uma amizade inocente, a ligação entre Jane e Helen ecoa as palavras da jornalista Stéphanie Arc:

\begin{abstract}
Aos gueis, a azaração e o sexo. Às lésbicas, a ternura e as carícias inocentes. Enquanto a homossexualidade masculina é posta sob o signo de uma sexualidade desenfreada, a relação feminina é, com freqüência, privada de sua dimensão física ou é atenuada, assimilando-se a jogos eróticos sem grandes consequências. Assim o amor entre mulheres é visto mais como cumplicidade afetuosa do que como relação tórrida. (ARC, 2009, p. 22)
\end{abstract}

Compreendo que o ponto de Arc possa ser extremista ao colocar a homoafetividade masculina como "azaração e sexo", especialmente quando se pensa no século XIX e a condenação, em 1835, de James Pratt e John Smith ${ }^{9}$. Entretanto, acredito que Arc expressa a invisibilidade das lésbicas enquanto temática não apenas literária. Considerando, por exemplo, o famoso caso de Oscar Wilde ${ }^{10}$, percebe-se que a sexualidade feminina é interpretada como uma amizade, um "jogo sem consequências", ou seja, algo menor que pode ser ignorado por não ser, de fato, sério. A sexualidade é diminuída, quiçá dessexualizada (nas palavras de Arc) por focar em relações sexuais. "Fantasias, atrações, emoções", diz Arc, são "os signos de uma eventual homossexualidade." (ARC, 2009, p. 22) Como ignorar, então, a fantasia de Jane ao criar Blanche na sua imaginação-arte?

Deslocar a leitura de Jane como uma mulher heterossexual para uma interpretação de como ela fora construída como tal significa expandir o campo crítico dos feminismos. Seguindo as brilhantes palavras da escritora Roxane Gay, todas as mulheres precisam ser incluídas no projeto feminista, pois muitas têm se distanciado cada vez mais deste pela ausência de integração em um Feminismo com $\mathrm{F}$ maiúsculo. (GAY, 2014, p. xiii) Ao reconhecer as falhas dos feminismos, Gay aponta que existem formas de ser feminista e abarcar todas as possibilidades do que significa ser mulher. Para tal, reconheço que ler o passado em busca do queer que sempre existiu é uma estratégia de abrir espaços para evitar os clichês perigosos de "Isso nunca existiu" ou "Na minha época não tinha isso". Além disso, buscar quão queer a literatura sempre foi significa expandir os próprios projetos da crítica literária feminista para o século XXI.

É de meu interesse aqui não tirar Jane do armário, mas tirar Jane da enfermaria para então mostrar como ela foi sempre interpretada. Saindo da enfermaria, enxergando a sua

\footnotetext{
${ }^{9}$ Pratt e Smith foram dois homens condenados à morte por sodomia, ou seja, a homossexualidade masculina não era apenas uma questão de "azaração e sexo" como Arc faz parecer.

${ }^{10}$ Resumindo de maneira sucinta, Wilde fora condenado a dois anos de prisão por ter cometido "atos imorais" com rapazes.
} 
própria arte como comunicação: só assim é possível puxar Jane Eyre para fora da zona de conforto. Só assim podemos colocar Jane Eyre dentro de feminismos e não mais um feminismo.

\section{REFERÊNCIAS}

ARC, Stéphanie. As lésbicas: mitos e verdades. São Paulo: GLS, 2009.

BRONTË, Charlotte. Jane Eyre. New York: Sterling Publishing, 2012.

ETCHEGOYEN, Ricardo Horacio. Fundamentos da técnica psicanalítica. Porto Alegre: Artmed, 2004.

FREUD, Sigmund. Um caso de histeria, três Ensaios sobre sexualidades \& outros trabalhos (1901-1905). Tradução de Paulo César de Souza. Rio de Janeiro: Imago, 1996.

FREUD, Sigmund. Deviant love. Tradução de Shaun Whiteside. London: Penguin, 2007.

GAY, Roxane. Bad feminist: essays. New York: Harper Perennial, 2014.

JAGOSE, Annamarie. Queer theory: an introduction. New York: New York University Press, 1996.

LOURO, Guacira Lopes. Um corpo estranho: ensaios sobre sexualidade e teoria queer. Belo Horizonte: Autêntica, 2016.

MISKOLCI, Richard. Teoria queer: um aprendizado pelas diferenças. Belo Horizonte: Autêntica, 2016.

RICH, Adrienne. Compulsory heterosexuality and lesbian existence. Journal of Women's History. Baltimore, v. 15, n. 3, p. 11-48, 2003. Disponível em $<$ https://www.jstor.org/stable/3173834> Acessado em 25 Jul 18.

SHOWALTER, Elaine. A literature of their own: British women writers from Charlotte Brontë to Doris Lessing. London: Virago, 2012.

VRETTOS, Athena. Somatic fictions: imagining illness in Victorian culture. Palo Alto: Stanford University Press, 1995.

Recebido em 27/07/2018. Aceito em 24/10/2018. 